\title{
Synthesis of N-doped P-type ZnO nanostructures by MOCVD method and formation of homo and hetero junction diode
}

\author{
Subhasish Patra ${ }^{1}$, Sachindranath Das ${ }^{1,}$ and Jae-Min Myoung ${ }^{2}$ \\ ${ }^{1}$ Department of Instrumentation Science, Jadavpur University, Kolkata 700032, India \\ ${ }^{2}$ Department of Material Science and Engineering, Yonsei University, Seoul 120-749, Republic of \\ Korea \\ *Email: sdas@isc.jdvu.ac.in
}

The major hurdle for the development of $\mathrm{ZnO}-$ based devices is the lack of good and reproducible p-type doping technology [1].Taking the strain effect, lattice mismatch and energy levels into account, $\mathrm{N}$ is a suitable acceptor for p-type $\mathrm{ZnO}$ owing to its small size mismatch with $\mathrm{O}[2]$. We have synthesized and studied the micro-structural, optical and electrical properties of $\mathrm{N}$ doped p-type $\mathrm{ZnO}$ nanostructures grown by MOCVD technique by using $\mathrm{NH}_{3}$ as $\mathrm{N}$ source. Both homo junction and hetero junction with this $\mathrm{N}$ doped $\mathrm{p}-\mathrm{ZnO}$ were formed by taking undoped $\mathrm{ZnO}$ and $\mathrm{GaN}$ as $\mathrm{n}$ side.

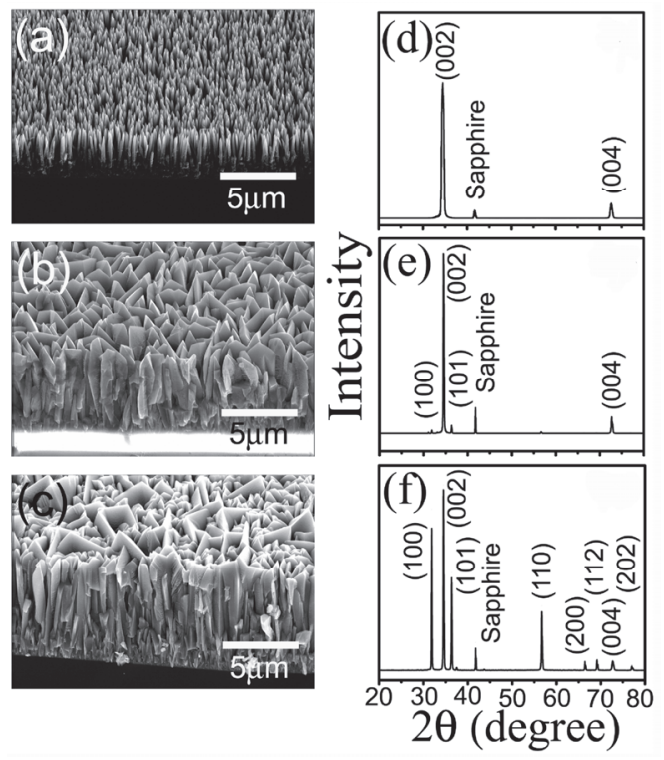

Figure 1: (a-c) FESEM image and (d-f) XRD pattern of samples. (a and d are for undoped and b, c, e and $\mathrm{f}$ are for doped $\mathrm{ZnO}$ samples).

The microstructures of $\mathrm{N}$ doped $\mathrm{ZnO}$ were highly influenced due to $\mathrm{N}$ doping (Figure 1). The XRD (Figure $1 \mathrm{~d}-\mathrm{f}$ ) shows that with introduction of $\mathrm{NH}_{3}$, more diffraction peaks arise and their relative intensities also
increase.The width and intensity of PL peaks are strongly influenced with increase of $\mathrm{NH}_{3}$ concentration during deposition. O substitution by $\mathrm{N}$ increases and more $\mathrm{N}_{O}$ defects appear in PL spectrum. The effect of oxygen vacancies was compensated by the effect of defect levels appears due to $\mathrm{N}$ doping, which causes the $\mathrm{p}$ type nature of $\mathrm{N}$-doped $\mathrm{ZnO}$. I-V characteristic of both type of junction (Figure 2) shows rectifying nature with high threshold voltage $(\sim$ $5 \mathrm{~V})$ and high reverse saturation current $(\sim$ $50 \mu \mathrm{A})$.
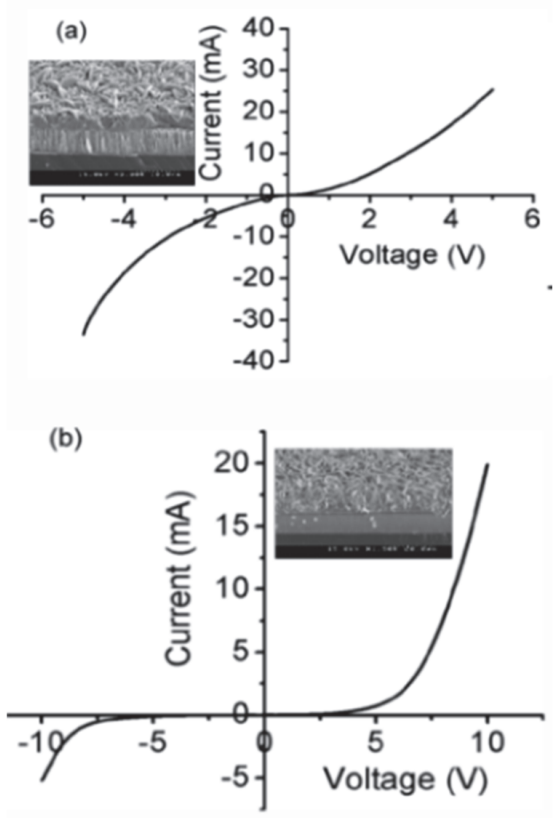

Figure 2: I-V characteristics of (a) homo junction (b) hetero junction of $\mathrm{ZnO}$ (inset shows corresponding SEM images)

\section{References}

1. Z. H. Zhang, Z. Z. Ye, T. Zhou, B. H. Zhao, Z. G.Fei, Mater.Lett. 59 (2005) 2732.

2. S. N.Das, J. H.Choi, J. P.Kar, T. I.Lee, J. M. Myoung, Mater. Chem. and Phys. 121 (2010) 472. 